$: \frac{9}{2}+74$

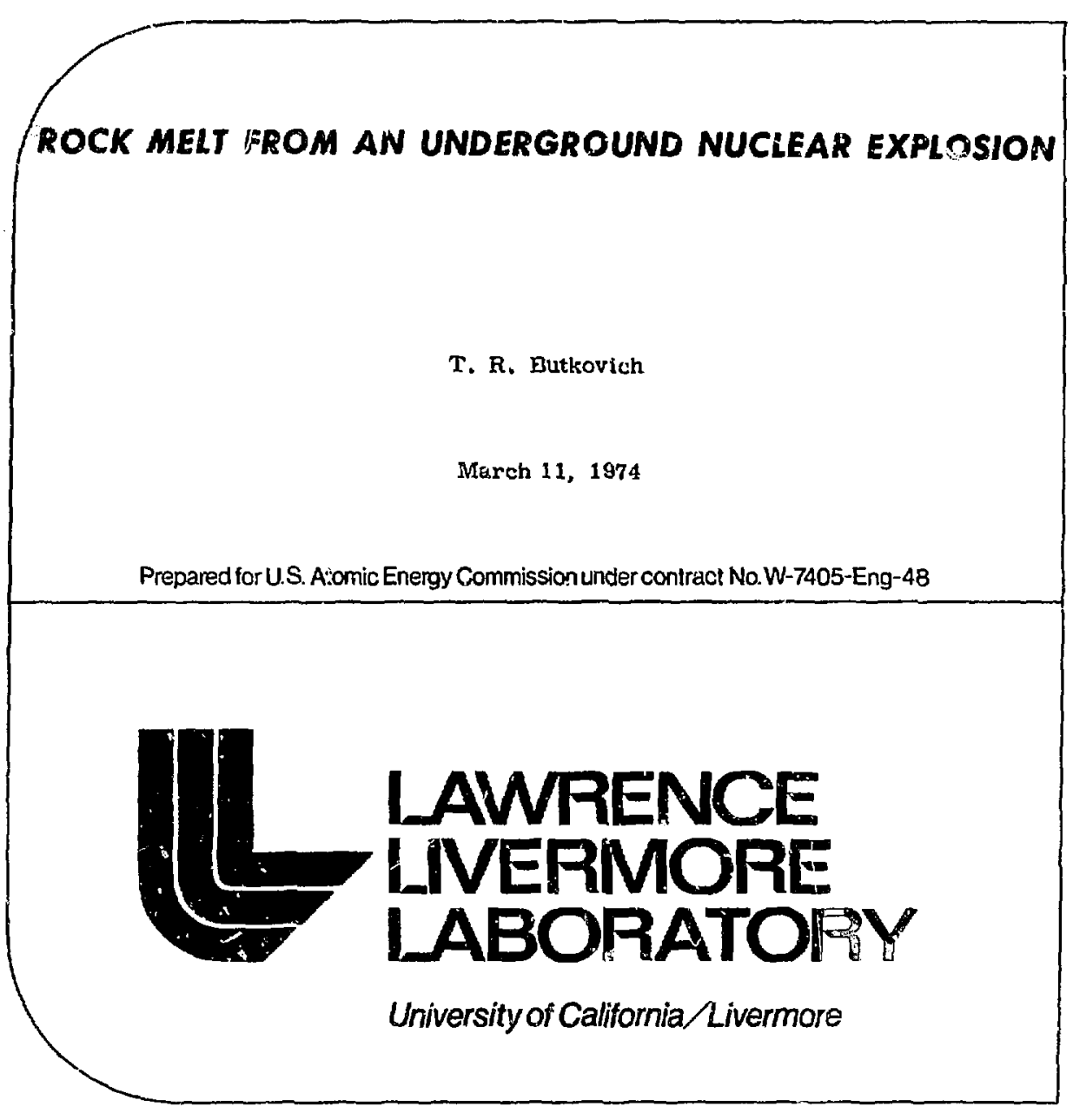


Notuct:

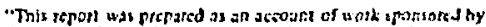
the United States Goretnment. Neltict the U'nitrd Stotes not

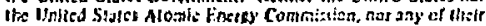

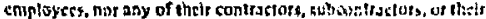

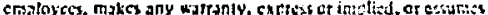

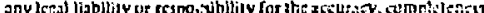

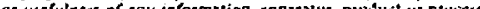

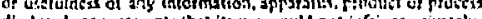

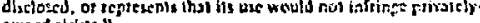
owned rightis."

Printed in the United States of America Available from

National Technical Information Service U.S. Depar'ment of Commerce 5205 Port Royal Road Springfield, Virgiria 22151

Price: Printed Copy $\$$ : Microfiche $\$ 0.95$

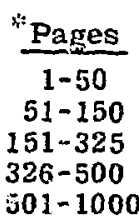

NTIS Selling Price

$\$ 4.00$

$\$ 5.45$

$\$ 7.60$

$\$ 10.60$

$\$ 13.60$ 
[II $-4500,16-35$

Peacelu! Applie'ations ui Livplestunn

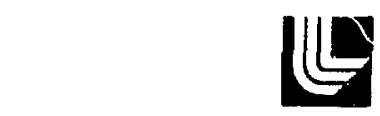

LAWRENCE LVERMORE LABORATOFY

Univorsityal Calioma Lvormoro. Cafiomia 94550

LCRR - 5155$\rfloor$

\section{POCK MELT FROM AN UNDERGROUND NUCLEAR EXPLOSION}

T. R. Bulkowich

MS. diste: March 11, 197.1

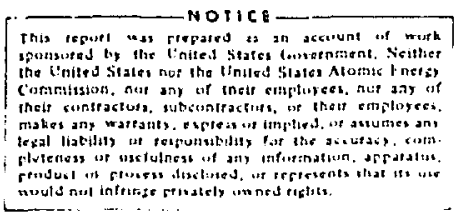

(1) 


\section{Contents}

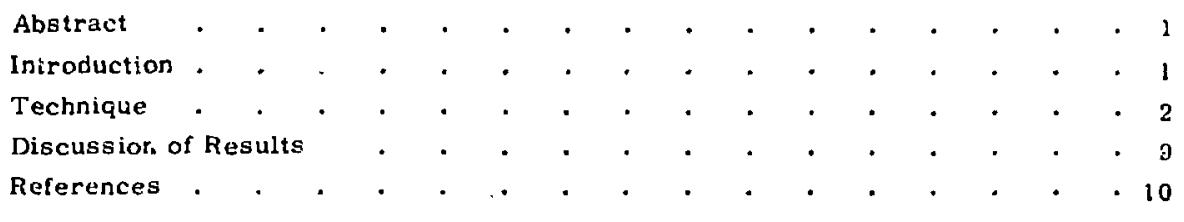




\title{
ROCK MELT FROM AN UNDERGFOUND NUCLEAR EXPLOSION
}

\begin{abstract}
Knowledge of the deposition of energy with distance around an underground nuclear explosion has significance in predicting chemical processes in the multimineralic rock substance surrounding the explosion. When a nuclear explosion is detonated, the shock wave that emanates $\mathrm{frcm}$ the explosion center does PdV work on the rock substance and deposits energy. Energy deposition due to the passage of the shock wave is determined from hydrodyramic code calculations which keep track of internal energy with distance and time. The energy distribution

with distance depends on the compressibility of the rock. Rock of low density and high porosity requires a larger increase in internal energy to shock it to a given pressure than an essentially pore-free dense rock. Interpretation of hydrodynamic: code calculations show's that 1000 to 1200 metric tons, $k t$ of melt is produced from dense granite and that two to three times as much melt is produced from dry porous ash-iall turt. Radiochemical analysis of melt samples recovered irom: near the shot point tend to confirm these results.
\end{abstract}

\section{Introduction}

Knowledge of the deposition of energy with distance around an underground nuclear explosion has significance in predicting chemical processes in the multimineralic rock substance surrounding the explosion. For example, the amount of noncondensable $\mathrm{CO}_{2}$ that is liberated from the carbonates present in many rocks is a function of the amount of carbonate in the rock structure and of the quantity of rock heated above the decomposition temperature of the carbonate. Other chemical processes in which $\mathrm{CO}_{2}$ is liberated can also occur; howe.er, knowledge of the energy distribution is necessary to make reasonable estimates of the amount of $\mathrm{CO}_{2}$ evolved. The $\mathrm{CO}_{2}$ acts as a diluent to other gases and raises the cavity pressure.

When a nuclear explosion is detonated. the shock wave that emanates from the explosion center is the primary means by which energy is distributed. The shock w ate cloes Pdl work on the rock substance and deposits some energy. Energy deposition due to the passage of the shock wave can be found from hydrodynamic codie calculations which keep track of the specific internal energy with distance and time.

One who is familiar with shock Hugoniots for rock and attenuation of the shock wave with distance might expect that the energy distribution for low-density, high-porosity rocks would be different from that for 
Inw-compressibility, high-density, essentially pore-free rock. The lowdensity rock requires a much larger increase in internal energy to shock it to a given pressure. Alsn, the shock wave is attenuated much more rapidly for a shot in a low-ciensity rock (Fig. 1), Consequently, it can be expected that more energy is deposited at higher temperatures in a low-density rack.

Previously reported calculations 1 indicate that approximately 10 metric tons/kt is dynamically shock vaporized and an additiona: $350 \mathrm{metric}$ tons/kt is dy'namicaily shock melted. However, these regions ale at a temperature significantly higher than itail required to just melt the rock. With a proper heat-transfer mechanism, much more rock could be melted. One can speculate as to what heat-transfer mechanistis are operating. Blow-oif of the walls of the cavity during the later part of the cavity expansion and mixing with its high-temperature contents seems likely. Ancither process is the transfer of heat to the already warm wall through radiation and convection, rasing the

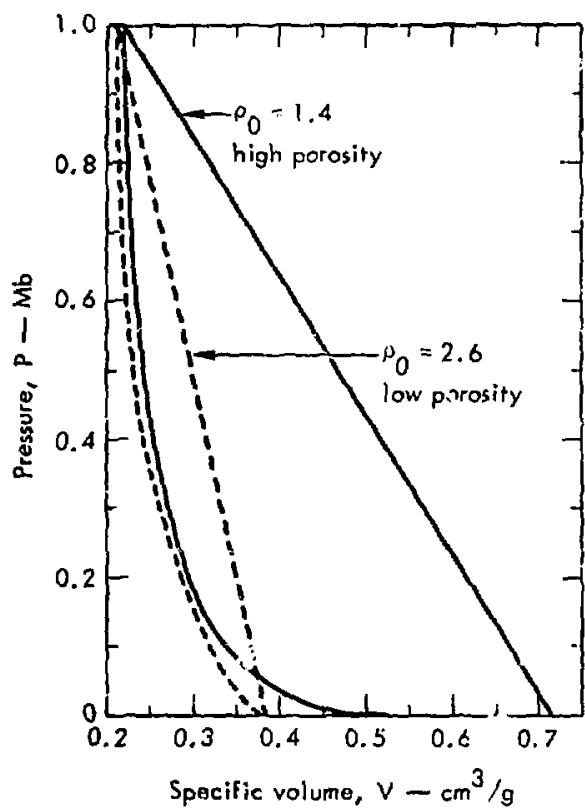

Fig. 1. Tyzical Hugoniot equations of state for high-density and lowcensity rocks.

temperature to the melting point, with the melt running or raining down under the influence of gravity, exposing more material to the hot cavicy environment.

\section{Technique}

SOC code calculations for materials of different densities were chosen from those that had previously been made. The shotpoint materials were a $1.4-\mathrm{g} / \mathrm{cm}^{3}$-density, high-porosity rock; a $1.81-\mathrm{g} / \mathrm{cm}^{3}$, mediumporosity rock; and a $2.61-\mathrm{g} / \mathrm{cm}^{3}$, low porosity rock. The Hugoniots f(r. these three rocks are shown in Fig. 2. The calculations were analyzed at late times after cavity growth was complete and the energy all distributed. Heat content was assumed to be the same for all three rocks; the value used was that for granite given by Birch ${ }^{2}$ and shown in Fig. 3.

From the energy-vs-scaled-distance relationship obtained from the SOC calculations and the heat-content relationship, a temperature-vs-scaled-distance curve was obtained for each density: these curves are shown in Fig. 4. The 


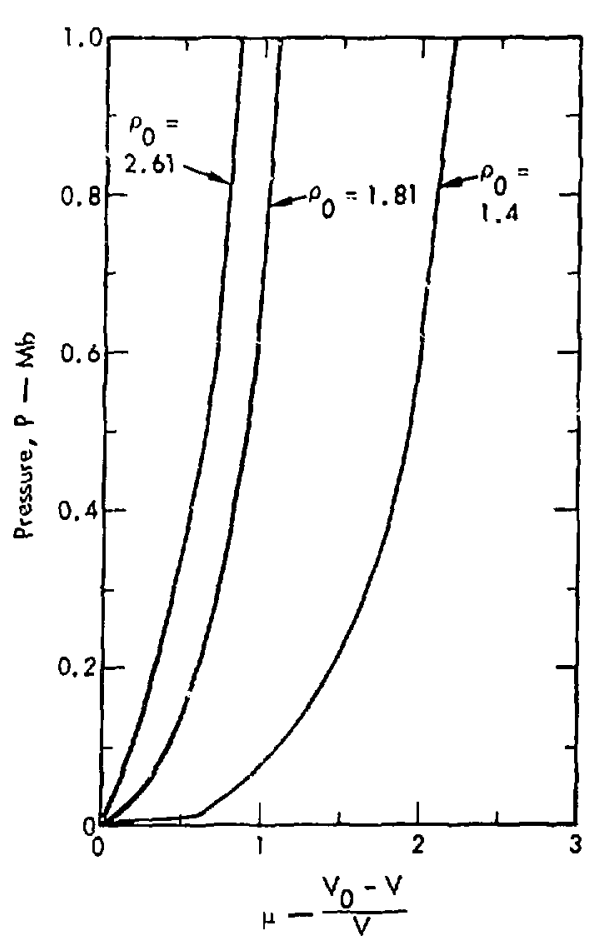

Fig. 2. Hugoniot equations of state used in this study.

equation for the straight line on a loglog plot is

$$
\Delta T=A\left(\frac{R}{w^{1 / 3}}\right)^{B}
$$

where $\Delta T$ is the increase in temperature above ambient in degrees centigrade (ambient is assumed to be $30^{\circ} \mathrm{C}$ ), $R$ is the distanct before displacament in meters, and $W$ is the explosion energy in kilotons $\left(10^{12}\right.$ cal $)$. The constants $A$ and $B$ are the intercept and slope, respectively, of the line. It was also possible to plot the

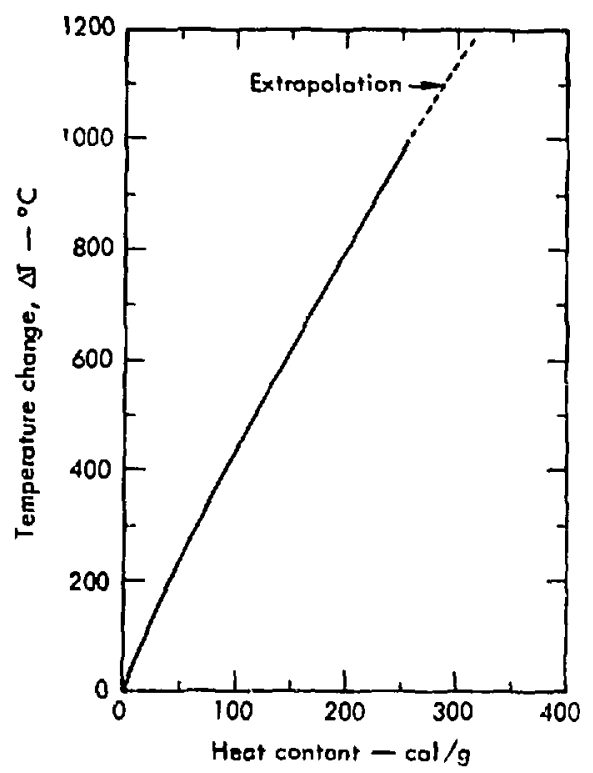

Fig. 3. Hieat content of rock as a funct in of temperature assumed in calculationg itiken from Ref. 2 ).

intercepts of the equation againgt densit and obtain a similar relationship:

$$
A=C(\rho)^{D} \text {. }
$$

where $\rho$ is the shot-point density in $\mathrm{g} / \mathrm{cm}^{3}$. For this case

$$
A=8.9 \times 10^{5} \rho^{-3.156} \text {. }
$$

Similarly, the slopes were plotted as a function of density and the relationship

$$
B=-4.576 \rho^{-0.411}
$$

was obtained. Equation (1) then bccomes

$$
\Delta T=\frac{3.9 \times 10^{5}}{\rho^{3.156}}\left(\frac{\mathrm{R}}{\mathrm{w}^{1 / 3}}\right)^{\frac{-4.570}{\rho^{0.41 !}}}
$$




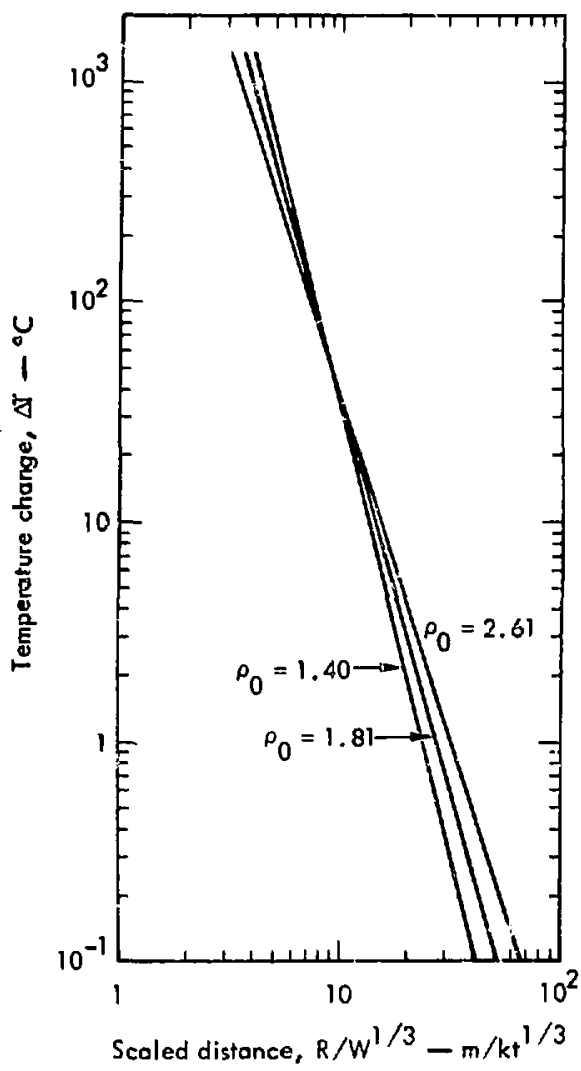

Fig. 4. Shock-induced temperature change as a function of scaled distance for nuclear detonations in rocks of different densities. From Eq. (4).

Table 1 shows the preshol distances for various temperatures and densities calculated from Eq. (4).

To obtain the relationship between the mass $M$ of rock heated to a temperature greater than any $\Delta T$, spherical symmetry was assumed so that

$$
M=\frac{4}{3} \pi R^{3} \text {. }
$$

Substituting for $B$ and solving for $M$, Eq. (4) becomes

$M=\frac{4}{3} \pi \rho W\left(\frac{\Delta T \rho^{3.156}}{8.9 \times 10^{5}}\right)^{\frac{-\rho^{0.411}}{1.5253}}$.

Using Eq. (5), it is possible to obtain the fraction of energy of the explosion between two temperatures. The integral $Q$ gives the total energy deposited:

$$
Q=\int_{T_{2}}^{T_{1}} E d M
$$

The relat:snship $b$, tween heat content and temperature from Fig. 2 was approxim ated by

$$
E=\left(\frac{\Delta T}{5.42}\right)^{1.048}
$$

Using Eqs. (5) and (7),

$$
\mathrm{Q}=\alpha\left(\mathrm{T}_{1}^{\beta}-\mathrm{T}_{2}^{\beta}\right) \text {. }
$$

where

$$
\begin{aligned}
\alpha=\left(\frac{4}{3} \pi \rho W\right) & \left(\frac{\rho^{3.156}}{8.9 \times 10^{5}}\right)^{\frac{-\rho^{0.411}}{1.5253}} \\
& \times\left(\frac{\rho^{0.411}}{1.5253}\right)\left(\frac{1}{5.42}\right)^{1.048} \\
& \times\left(1.048-\frac{\rho^{0.411}}{1.5253}\right)
\end{aligned}
$$

and

$$
\beta=1.048-\frac{\rho^{0.411}}{1.5253} \text {. }
$$


Table 1. Distances for various temperatures and shot-point densities $\left(\rho_{0}\right)$.

\begin{tabular}{|c|c|c|c|c|c|c|c|}
\hline \multirow{2}{*}{$\begin{array}{c}\text { Yield } \\
(\mathrm{kt})\end{array}$} & \multicolumn{7}{|c|}{ Distance $(\mathrm{m})$ at temperature } \\
\hline & $1000^{\circ} \mathrm{C}$ & $500^{\circ} \mathrm{C}$ & $300^{\circ} \mathrm{C}$ & $200^{\circ} \mathrm{C}$ & $100^{\circ} \mathrm{C}$ & $10^{\circ} \mathrm{C}$ & $1^{\circ} \mathrm{C}$ \\
\hline \multicolumn{8}{|c|}{$\rho_{0}=1.4 \mathrm{~g} / \mathrm{cm}^{3}$} \\
\hline 1 & 4.21 & 5.01 & 5.70 & 6.31 & 7.50 & 13.37 & 23.83 \\
\hline 10 & 9.07 & 10.80 & 12.27 & 13.59 & 16.17 & 28.21 & 51.35 \\
\hline 100 & 19.54 & 23.26 & 26.44 & 29.27 & 34.83 & 62.07 & 110.63 \\
\hline \multicolumn{8}{|c|}{$\rho_{0}=2.0{\mathrm{~g} / \mathrm{cm}^{3}}^{3}$} \\
\hline 1 & 3.81 & 4.66 & 5.40 & 6.08 & 7.44 & 14.51 & 28.34 \\
\hline 10 & 8.21 & 10.04 & 11.64 & 13.10 & 16.02 & 31.28 & 61.06 \\
\hline 100 & 17.68 & 21.63 & 25.08 & 82.22 & 34.52 & 67.79 & 131.56 \\
\hline \multicolumn{8}{|c|}{$\rho_{0}=2.6 \mathrm{~g} / \mathrm{cm}^{3}$} \\
\hline 1 & 3.39 & 4.25 & 5.01 & 5.71 & 7.15 & 15.06 & 31.73 \\
\hline 10 & 7.71 & 9.15 & 10.79 & 12.31 & 15.40 & 32.46 & 68.73 \\
\hline 100 & 15.75 & 19.71 & 23.26 & 26.52 & 33.19 & 69.92 & 147.29 \\
\hline
\end{tabular}

Figure 5 shows a plot of Eq. (8) in terms of temperature vs fraction of total energy between $\mathrm{T}_{1}=1000^{\circ} \mathrm{C}$ and $\mathrm{T}_{2}$ $=0.01^{\circ} \mathrm{C}$. Note that about $25 \%$ of the energy is between these two teriperatures for the shot-point density $\rho=1.4 \mathrm{~g} / \mathrm{cm}^{3}$, aind about $72 \%$ of the energy is between these two temperatures for $\rho=2.8 \mathrm{~g} / \mathrm{cm}^{3}$, with a varying fraction between these limits for other censities in this range.

The integration gi'es the amount of energy at temperatures outside of $T_{1}$, which can be considered the melt temperature. By assuming that the energy which is not ouiside the melt temperature is in the melted rock, the mass of rock melted can be calculated. Table 2 shows the fraction of eneigy outside the melt calculated from Eq. (8) with various $T_{1}$ (melt temperatures) and $T_{2}=0.001^{\circ} \mathrm{C}$ for different shot-point densities. Figure 6
Table 2. Fraction of energy outside of different melt temperatures for different shot-point densities $\left(\rho_{0}\right)$.

\begin{tabular}{|c|c|c|c|c|c|}
\hline \multirow[b]{2}{*}{$\left.\rho_{0} \lg \cdot \mathrm{cm}^{3}\right)$} & \multicolumn{5}{|c|}{ Eneray iraclion al temperature } \\
\hline & $1-00+c$ & $1200 \cdot \mathrm{C}$ & 1000 & $\therefore 006$ & 1,1000 \\
\hline 1.4 & 0.2637 & 0.25 .55 & 9.2 .517 & 0.2245 & איוויגנית \\
\hline 1.6 & 0.3315 & 0.3161 & $0,2 ! 187$ & $0.25: i t$ & 0,2 . . . \\
\hline 1.8 & 0.3964 & 0.3806 & 0.3021 & $4 . .+4) d e$ & $0,31 \%$ \\
\hline 2.0 & 0.4626 & $0.4+59$ & $1,+20 u$ & 0.4040 & $0.7 \%$ \\
\hline 2.2 & $0.5+14$ & 0.5243 & $0.504 \hat{\imath}$ & 0.4 ifli & 0.4 .63 \\
\hline$? .4$ & $0 .+22 !$ & 0.6057 & $0.506 !$ & $0.362 !$ & $0.8,+3 t 1$ \\
\hline 2.6 & 0.7125 & 0.6950 & 0.15761 & $0.6,0^{3}:$ & $0.62+0$ \\
\hline 2.8 & 0.1221 & 0.7956 & 0.771 .5 & 0.5536 & $0.5+4 \pi$ \\
\hline
\end{tabular}

shows the fraction of melt above $T_{1}$ (1 minus the values in Table 2 ).

Table 3 shows the amount of melt calculated as a function of density and assumed melt temperatures by dividing the fraction of energy in the melt by $\Delta \mathrm{H}_{\text {melt }}$, the enthalpy for melt. $\Delta H_{\text {melt }}$ values were obtained, by extrapolating the values in Fig. 2, as the specific energy to raise 


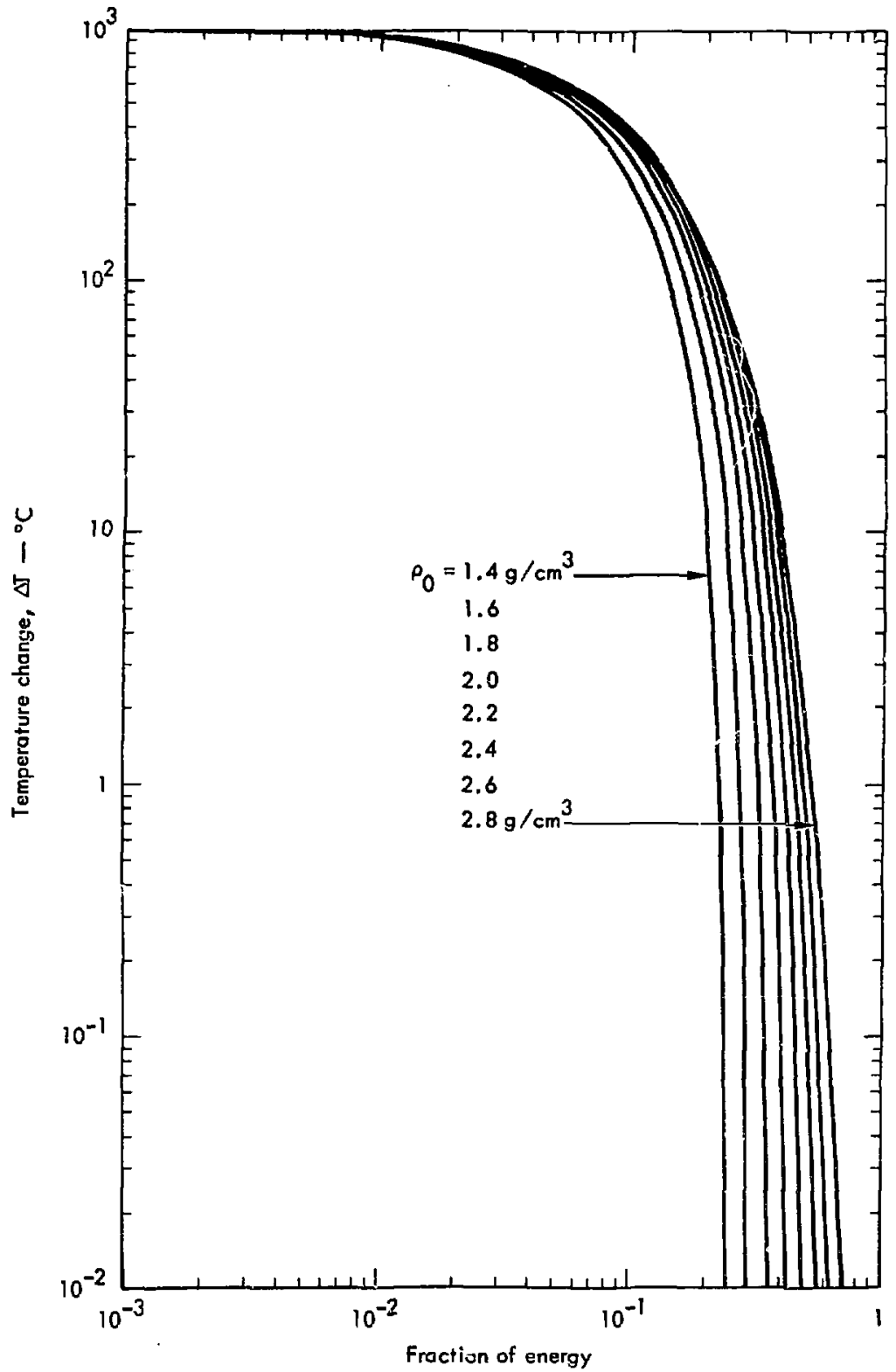

Fig. 5. Fraction of energy in rock between assumed melt temperature of $1000^{\circ} \mathrm{C}$ and lower temperatures for rocks of different shot-point densities. 
Table 3. Mass of rock melted for rocks of different densities $\left(\rho_{0}\right)$ and different assumed meli temperatures and enthalpies $\left(\Delta \mathrm{H}_{\text {melt }}\right)$.

\begin{tabular}{|c|c|c|c|c|c|}
\hline \multirow[b]{2}{*}{$\rho_{0}\left(5, \mathrm{cnt}^{3}\right)$} & \multicolumn{5}{|c|}{ 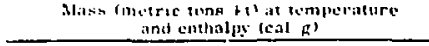 } \\
\hline & $\begin{array}{c}100^{\circ} 0 \\
+19\end{array}$ & $\frac{11000}{393}$ & $\underset{5.36}{1000^{\circ} \mathrm{C}}$ & $\begin{array}{c}1300^{\circ} \mathrm{C} \\
\geq 80\end{array}$ & $\begin{array}{l}1000 \\
224\end{array}$ \\
\hline 1.4 & 1650 & 1484 & $\ldots .3$ & 2740 & 1570 \\
\hline 1.6 & $1+89$ & $17: 0$ & 5015 & $2 \sin 6$ & 1927 \\
\hline 1.8 & $1: 343$ & 1576 & 1801 & 2355 & 30 st \\
\hline 2.0 & 1197 & 1410 & 1706 & 2126 & 2770 \\
\hline 2.2 & 1021 & 1210 & $1+7+$ & 1851 & 24ง \\
\hline 2.4 & 340 & 1003 & 1232 & $|s t|$ & 2080 \\
\hline 2.6 & $6+0$ & 775 & 964 & 1280 & 1679 \\
\hline 2.8 & 418 & 520 & 265 & nขa & $122 !$ \\
\hline
\end{tabular}

the rock to the melt temperature plus the latent heat of fusion, which was assumed to be $80 \mathrm{cal} / \mathrm{g}^{2}$

The calculations show that the amount of rock that is potentially melted by an underground nuclear explosion is a rather strong function of the density of the shotpoint material. Fortunately, there are data available to check these results. G. Higgins ${ }^{3}$ suggested analyzing the radiochemical data on melt samples recovered from near the explosion center on many nuclear events at the Nevada Test Site. On the basis of experimental meas urements, it is generally assumed that all refractory nuclides are associated with the melt. ${ }^{4}$ Melt puddle samples are recovered in postshet drilling and analyzed in the laboratory as to the fraction of activity of various refractory isotopes produced by the nuclear explosion. If one assumes that the melt is perfectly mixed and the samples are representative of all the melt, then the amount of melt produced per kiloton can be obtained. Six to fourteen puddle samples are measured for each event, and the fractions of activity for a number of different refraciory isotopes are obtained. For the present study, radio-

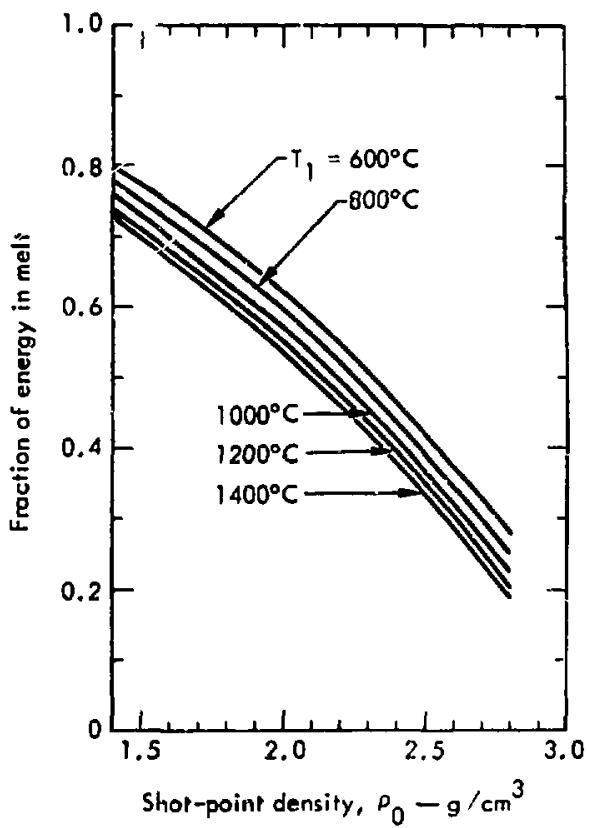

Fig. 6. Fraction of energy in rock melt vs shot-point density assuming different melt temperatur's.

chemistry data were analyzed for about 40 events; however, shot-point densities are available for only about half of these.

There is considerable scatter in the results of the measurements. Figure 7 shows the amount of melt per kiloton of yield vs shot-point density. The points were obtained by averaging the radiochemical measurements on puddle-glass samples. The standard deviation is about $50 \%$ of the average values shown. There is some question of whether the radiochemical samples are representative of the puddle glass; sample descriptions indicate that some contain impurities such as water and drilling mud. One would then expect that those samples that were 


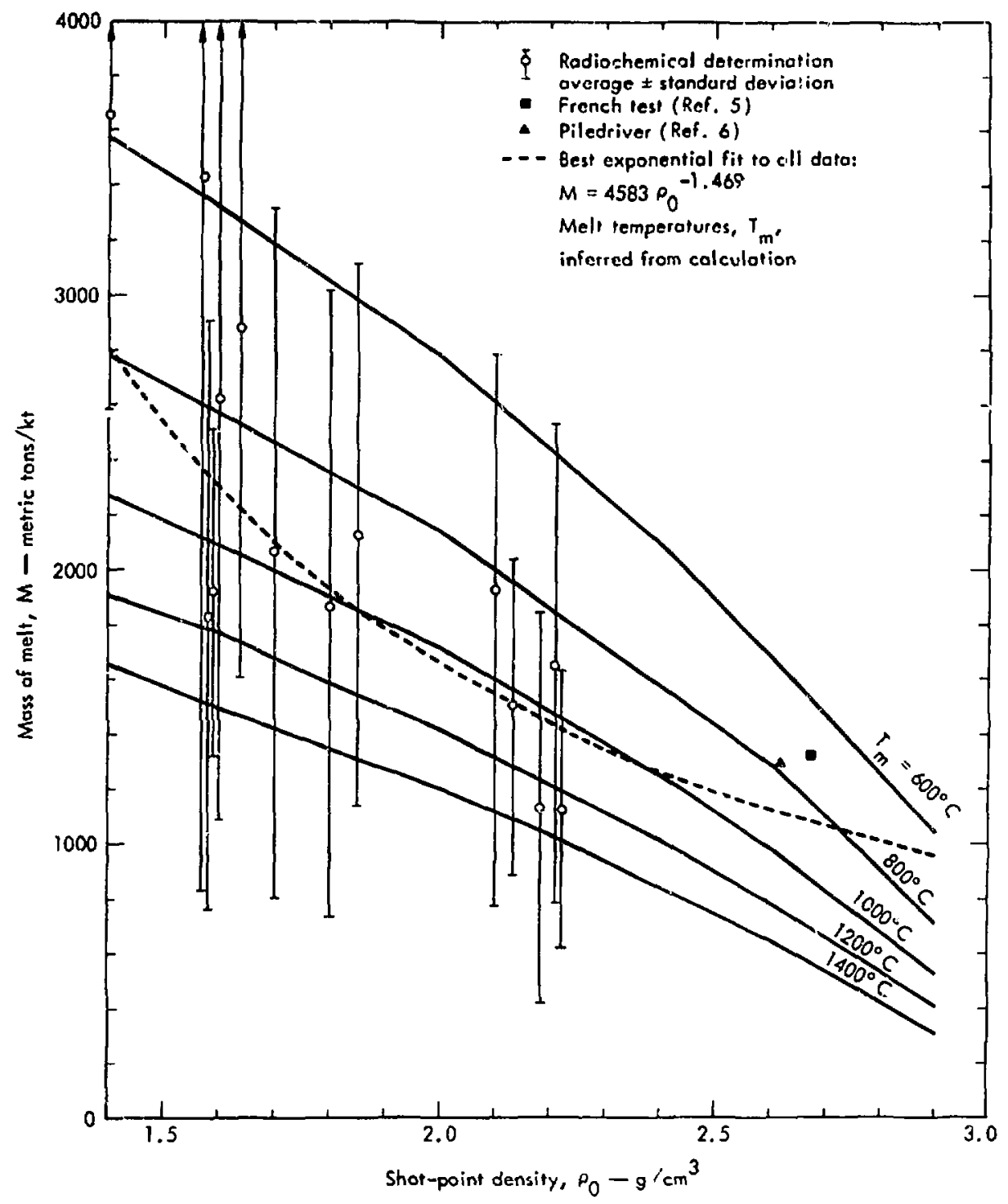

Fig. 7. Calculated amount of melt per kiloton vs shot-point density assuming different melt temperatures. Mean values from radiochemical determinations are shown for LLL data along with their standard deviations. Direct dete -minations from a French test and from the Piledriver Event are also shown. 
indicated to contain impurties would consistenily give higher values for sizount of melt. Howevar, if these ditferences exist, they are hidclen in the scatter of the data. Two additional data poin:s obtained by other techniques are also shown. Cohen ${ }^{5}$ shows values obtained in a granite in which the Fronch underground tests were conducted, and Borg ${ }^{6}$ obtained an amount of melt for the Piledriver Event, also in granite. Figure? also sho'vs the exponential best fits to the data, along with melt temperatures inferred from calculations given in Table 3.

\section{Discussion of Results}

in an underground nuclear explosion, the total amount of rock melt produced dynamically by the shock wave and by the redistribution of the excess heat appears to be a function of the slict-point density. This result is obtained calculationally, and it is supnorted by experimental evidence. Although there is a large scatter in the radiochemical results, there is a definite $t r$ and toward more melt produced in lower-density (higher porosity) shot-point media. The large scatter of the radiochemical results can be attributed in part to the sampling techniques, whereby considerable impirities are included in the melt samples. The total melt produced appears to range between about 1300 metric tons/kt of cncrgy yield for the high-densily, low-porosity shot-point rocks to two to three times this amount for the low-density, high-pornsity shotpoint rocks.

The water content of the shot-point rock was not taken into consideration cither in the calculations or in estim ating a melt temperature for shots in which radiochemical data were available. Witer content has two important effects: The first is that increasing water content iends to depress the melting temperature of the rock. ${ }^{7}$ The other is that an increased water content increases the heal content of the rock, since the average specific heat of the water component of the rock is about five times greater than that of the solid component. 


\section{References}

1. T. R. Butkovich, Gas Equation of State of Natural Materials, Lawrence Livermore Laboratory, Rept. UCRL-14729 (January 1967 ).

2. F. P. Birch, Ed, , Handbook of Physical Constants, GSA Special Paper No. 36 (1942).

3. G. Higgins, Lawrence Livermore Laboratory, private communication.

4. H. A. Tewes, H. B. Levy, and L. L. Schwartz, Nuclear Chemical Copper Mining Radiological Considerations, Lawrence Livermore Laboratory (to be published).

5. P. Cohen, Gases Formed in an Underground Nuclear Explosion: Chemical Equilibria and Potential Application, Lawrence Livermore Laboratory, Rept. UCRL-Trans10616-3 (1972) (translation of IAEA-PL-388/7, pp. 199-209, 1970).

6. i. Y. Borg, Long-Lived Radionuclides Contained in Glasses Produced by Nuclear Explosion in Granodiorite (Piledriver Event), Lawrence Livermore Laboratory. Rept, UCRL-7.4588 (1072).

7. A. J. Piwinskii and R. F. Martin, "An Experimental Study of Equilibrium with Granite Rocks at $10 \mathrm{~kb}$, " Contrib. Mineral, Petrol. 29, 11970 ). 